\title{
IMPROVING ORGANISATIONAL PERFORMANCE THROUGH HIGH PERFORMANCE WORK PRACTICES
}

\author{
Liz Kennedy ${ }^{1}$ \\ University of Westminster, London, England
}

What are High Performance Work Practices and to what extent can they be found in Romanian organisations? Researchers from the University of Westminster in London who are currently conducting a study of comparative Human Resource practices in Romanian organisations are attempting to provide answers to these questions. The stimulus for the research arose from a Master's programme in Human Resource Management delivered in Romania to $\mathrm{HR}$ professionals and the initial aims were to explore comparative HRM philosophies, systems and practices in Romania and the West and to make a contribution to thinking about European HRM. Although this started as a small scale qualitative study, the results have been very encouraging and further work is planned including in-depth qualitative studies and quantitative data gathered by questionnaire from a cross section of Romanian organisations. It is hoped that the results will be useful for Romanian businesses, particularly in light of the EU accession.

Analysis of the initial research findings from the first case study organisations focused the next stage of the research onto the existence of particular HR practices and the relationship between these practices, leadership style and organisational culture.

In the constant search for organisational improvement, management researchers have turned their attention to assessing the impact of different kinds of HR policies and practices on organisational performance (Sung and Ashton, 2005; Holbeche, 2003;) Various studies (Sung and Ashton, 2005: Wales Management Council, 2005) have shown links between certain kinds of HR practices and improved productivity and profitability, increased sales and market value. These practices have been shown to be more effective under certain conditions. Firstly, their impact is dependant on the leadership culture of the organisation. To be effective they require a culture of empowerment with high employee involvement. Enabling leadership with a clear

\footnotetext{
${ }^{1}$ Adresa de contact: info@lizkennedy.co.uk
}

vision for the future is a must. A negative work climate characterised by micro-management, authoritarian leadership and inequitable rewards will inhibit their effectiveness. Secondly, the practices have more impact when they are grouped or 'bundled' together.

So what are these practices? They are not necessarily new and may be seen by many employers as simply common sense, but for others they may involve a wholesale culture change. The practices can be grouped into three clusters:

- High Involvement Practices: these encourage a much greater level of trust and communication between employers and employees by involving employees more in the organisation. High involvement is accompanied by a high degree of employee empowerment and the exercise of discretion. Included in this category are internal staff surveys, staff suggestion schemes, quality circles and total quality management, self directed and cross functional teams, staff associations and continuous improvements in working practices. Involving employees by giving them information about the organisation's strategy and business plan would also fall into this category.

- Human Resource Practices: these are specifically targeted to create a greater depth of human capital investment. The higher levels of skill that result from these practices are linked to improvements in the quality of work and service to the customer. Many of these practices are designed to encourage a climate for development and include annual appraisal, regular feedback on performance, learning and development tools such as mentoring, continuous skills development programmes, induction training, workforce diversity and quality assurance programmes such 
as ISO 9000. A focus on formal assessment processes for recruitment is also included in this cluster as is the process of designing work to improve performance.

- Reward and Commitment Practices: these facilitate a greater sense of belonging and commitment to the organisation, establish a sense of stake holding and recognise the contribution of individuals and teams. This cluster focuses not only on reward practices such as performance pay, profit sharing, share options and non pay benefits, but also on issues around flexible working including job rotation and family friendly policies.

The effects of High Performance Work Practices indicate a strong link with productivity and profitability and these links are found across countries and in different sectors. They deliver significant employee benefits including increased staff satisfaction, motivation and commitment. Improved quality of leadership and team working is observed and organisations using these practices are likely to be more effective at introducing and managing change.

However, these practices are only likely to be effective if they are operating in a positive work climate. A positive work climate is characterized by empowerment of staff, giving staff responsibility and encouraging all to take responsibility for their own actions, team commitment, appropriate recognition and reward and, perhaps most importantly, an enabling leadership style. A negative work climate would involve micro-management, high control, excessive centralization, inequitable rewards, lack of responsibility and authoritarian leadership.

Our research looked at eight companies operating in Romania ranging from large multinationals to a small Romanian owned IT company. Interviews were conducted to explore issues of culture, leadership and Human Resource practices. We found evidence of High Performance Work Practices in the entire sample of companies.

Most commonly, the practices fell under the Human Resource Practice cluster. Many organisations were operating sophisticated performance management systems which included appraisal, regular feedback to staff, and regular one to one sessions. The process of cascading company objectives was well developed, with team and individual goals linked to organisational objectives. There was evidence of the effective use of these systems to drive performance and embed cultural change. For example, a large brewery was using their performance management system in a helpful and sophisticated way to ensure a smooth merger with a newly acquired company, helping to embed new cultural norms and ways of working. Also common in our sample was the use of formal assessment tools for recruitment including extensive use of tests and assessment centres. Skills development programmes, structured induction training and annual reviews of training needs were also common. Many organisations had gone down the quality assurance route.

There was also some evidence of High Involvement Practices particularly staff surveys, and the provision of information on organisational performance. There were some examples of self directed teams and of cross functional team work. For example, one company in our sample used a cross functional group of employees from across the organisation to develop a new pay and reward structure. A brewery company encouraged staff to be involved in the quality of the product by using them as 'testers' for the beer.

The least commonly occurring practices were in the Reward and Commitment cluster. We found little evidence of profit sharing, performance pay for all, flexible working or family friendly polices. Very few organisations had a policy on workforce diversity, or practices that encouraged minority groups to take an active role in the organisation.

So what can we learn from this? First of all that some Romanian organisations are successfully using some high performance work practices to improve their performance, although there is still some way to go particularly in the cluster of Reward and Commitment. Secondly, the study underpinned the crucial role of leadership style and empowerment to facilitate the impact of these practices. Many organisations were running leadership development programmes and some were specifically targeting first line managers to introduce them to a more team based, less authoritarian style. Organisations were attempting to shift the culture and expectations of employees from wanting to be told what to do to wanting to be part of the decision making process.

Further research on leadership led us to conclude that while there is evidence of good modeling of the new empowering leadership 
agenda in Romania, there are also cultural blockages to the adoption of this approach (Dalton and Kennedy, 2007). These include a short term, operation focus by many leaders rather than a strategic focus, an autocratic style operating in some areas coupled with a deference to higher authority and, in some instances a paternalistic approach. Of prime concern is a lack of openness and trust, leading to over- controlling behaviour which in turn leads to a negative work climate. Also, some managers and leaders expressed doubts about the future direction of their organisations and whether it was safe to experiment with new approaches to leadership.

Summing up some key lessons for HR practitioners and others concerned with improving their organisation, we would highlight the following:

- Your organisation needs empowering leadership with a clear vision if the High Performance Work Practices are to be effective. Providing support and training to help all leaders to understand and work towards adopting this style is a must. If leaders welcome ideas and challenges from staff, then the product will be better. In a culture where people are not afraid to speak out and alternative views are encouraged, accidents are less likely to happen.

- Encourage a culture of feedback where people become used to reviewing their own and others performance to ensure that they are continually improving. Regular one to one feedback has been shown to be a key factor in improving organisational and individual performance.

- Adopt those High Performance Work Practices that are most suitable for your culture, bearing in mind that 'bundles' of practices are more effective than one or two on their own. But be careful of buying 'off the shelf' practices that don't fit with your organisation strategy or culture.

- Ensure that you have systems in place to learn from mistakes and feed the data gained from this into the decision making processes used to avoid accidents and manage risks. Develop your organisational culture so that it is a 'constructive problem solving' culture rather than a 'blame - defend' culture.

There are benefits here not only for individual organisations, but also for Romania as a whole. Well managed organisations with a culture of empowerment and high involvement could be a powerful force for change, bringing skills and knowledge from the workplace into all aspects of civil society.

\title{
D\&D Consultants, Bucureşti www.ddconsultants.ro
}

\author{
Instrumente psihometrice publicate de D\&D Consultants / TestCentral \\ - CPI: California Psychological Inventory $(462,434,260)$ \\ - NPQ: Nonverbal Personality Questionnaire \\ - FFNPQ: Five-Factor Nonverbal Personality Questionnaire \\ - SWS: Survey of Work Styles \\ - STAXI-2: State-Trait Anger Expression Inventory \\ - FPI: Freiburger Personlichkeitsinventar (Formele G si R) \\ - LSI: Learning Styles Inventory \\ - MLQ: Multifactor Leadershp Questionnaire (Forma 5X) \\ - STAI: State-Trait Anxiety Inventory \\ - STAIC: State-Trait Anxiety Inventory for Children \\ - JVIS: Jackson Vocational Interest Survey \\ Instrumente psihometrice în curs de apariție \\ - AMI: Achievement Motivation Inventory \\ - ASSET: A Shortened Stress Evaluation Tool
}

